\title{
C4 Deficiency
}

National Cancer Institute

\section{Source}

National Cancer Institute. C4 Deficiency. NCI Thesaurus. Code C119993.

Lack of production of functional C4 protein, due to a genetic defect requiring homozygous loss of both the C4A and C4B genetic paralogs. Approximately $75 \%$ of patients with a C4 deficiency will develop a severe systemic lupus erythematosus at an early age. Patients also present with frequent sinopulmonary infections often with Streptococcus pneumoniae. 